\title{
In situ gold-nanoparticle electrogeneration on gold films deposited on paper for non-enzymatic electrochemical determination of glucose
}

Estefanía Núnez-Bajo

M. Carmen Blanco-López

Agustín Costa-García

M. Teresa Fernández-Abedul

mtfernandeza@uniovi.es

Departamento de Química Física y Analítica, Facultad de Química, Universidad de

*Corresponding author

Abstract

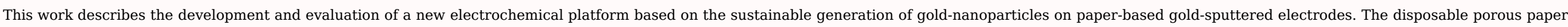

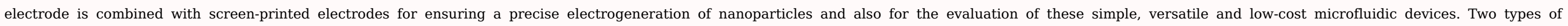

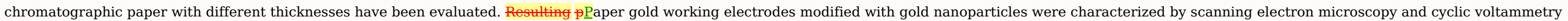

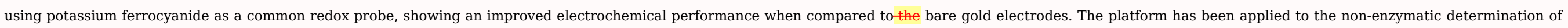

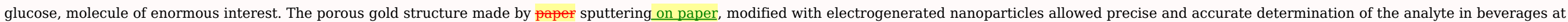
low potential.

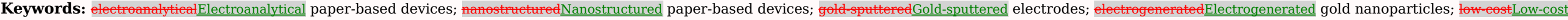
decentralized analysis; enzymatieNon-enzymatic glucose analysis

\section{Introduction}

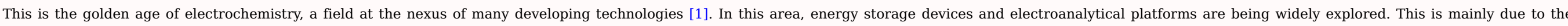

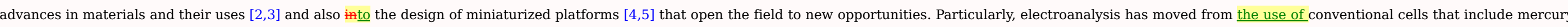

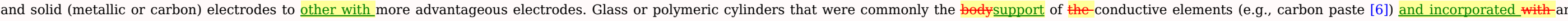

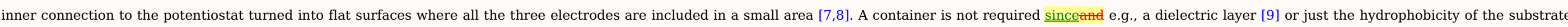
[10] eliminates its necessity.

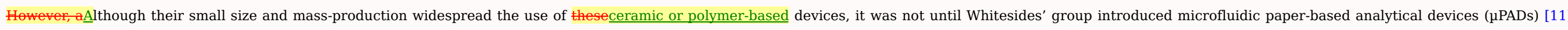

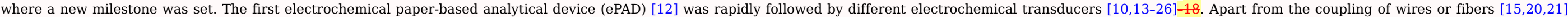

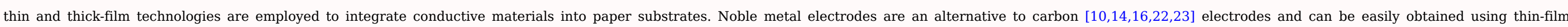
technologies $[17,24-26]$ that maintain the 3D porous structure of paper and do not require printing inks or curing processes.

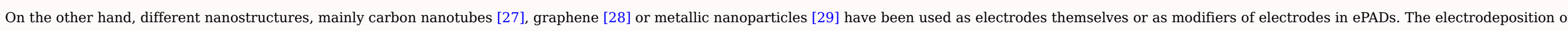

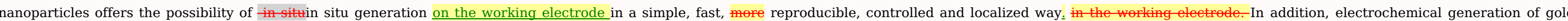

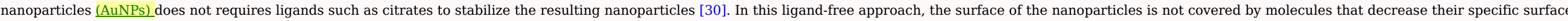

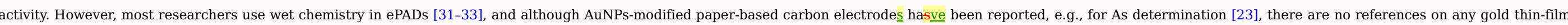




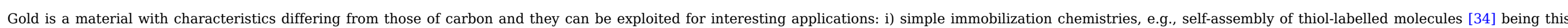

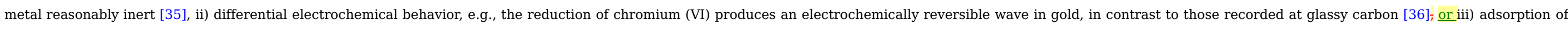
species, e.g., heteropolyanions, that occurs with different intensity depending on the electrode material [37].

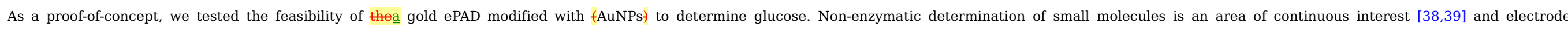

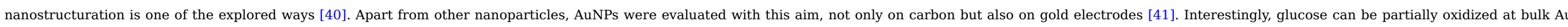

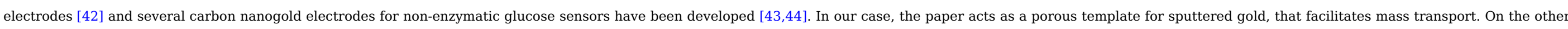

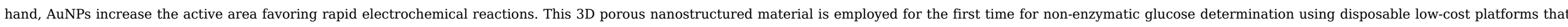
are a promising alternative to AuNPs-carbon ePADs for decentralized analysis.

\section{Experimental}

\subsection{Chemicals, materials and apparatus}

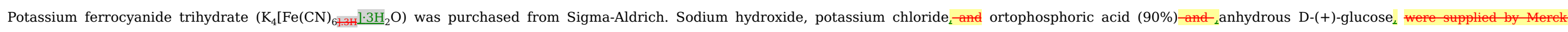
and Titrisol® Gold-Standard (10.15 $\mathrm{mM} \mathrm{AuCl}_{4}{ }^{-}$in $2.0 \mathrm{M} \mathrm{HCl}$ solution)

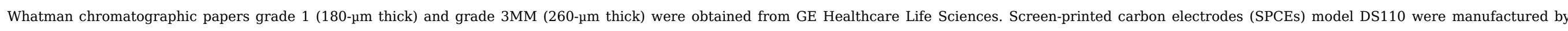
DropSens.

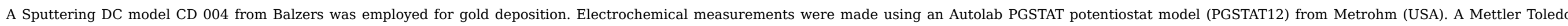
(AB54) balance, a Crison Micro-pH 2001 pH-meter, a magnetic stirrer Asincro (J.P. Selecta), Digital Multimeter Model (DT9205A) were also employed.

\subsection{Fabrication of paper-based gold electrodes}

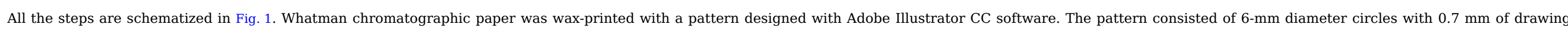

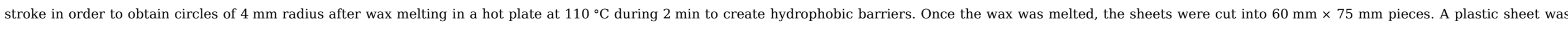

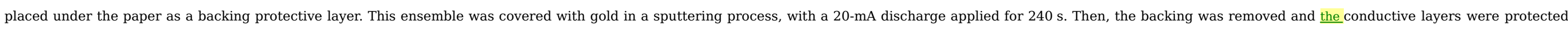

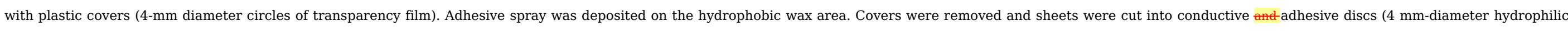
area and 0.5-mm hydrophobic adhesive rim) using a paper punch.

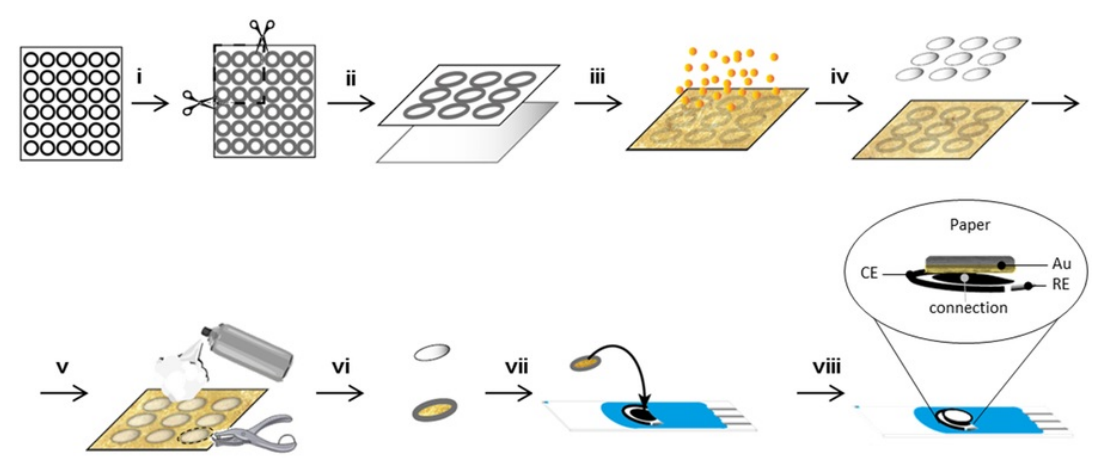

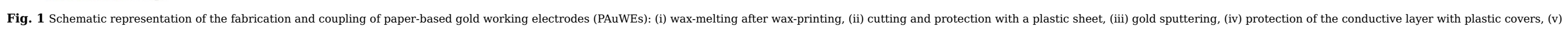
addition of adhesive in spray, (vi) removal of plastic cover after cutting the PAuWE, (vii) placement over the working electrode of the SPCE, (viii) final platform composed by the PAuWE with external reference and counter electrodes from the SPCE. 


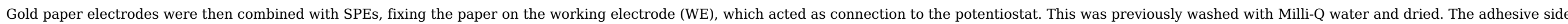

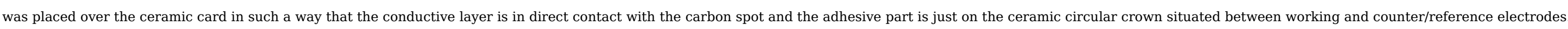

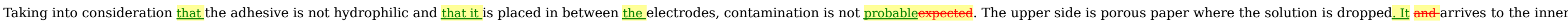

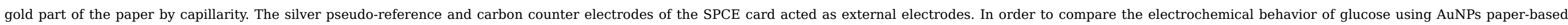
carbon electrodes, drop-casted carbon electrodes were prepared as reported in a previous work [23].

\subsection{Characterization of paper-based gold electrodes modified with gold nanoparticles}

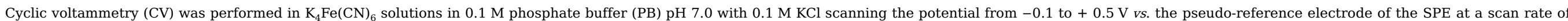
$100 \mathrm{mV} \mathrm{s}^{+\frac{4-1}{}}$.

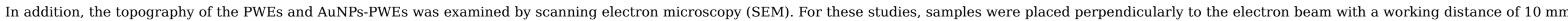
and $20 \mathrm{kV}$ of extraction tension in a JEOL (model 6610LV) microscope.

\subsection{Glucose determination in real samples}

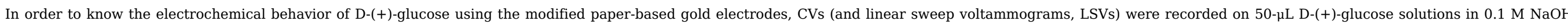
scanning the potential in different windows at a scan rate of $100 \mathrm{mV} s \underline{\mathrm{mV}} \mathrm{s}^{\mathrm{q}-1}$

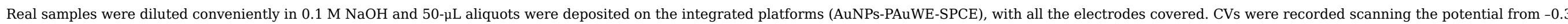

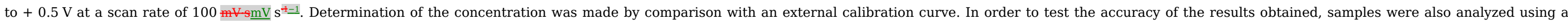
commercial glucose kit with spectrophotometric detection.

\section{Results and Điscussiondiscussion}

\subsection{Fabrication and characterization of nanostructured paper-based gold electrodes}

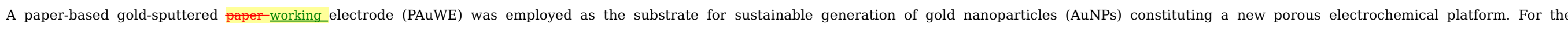

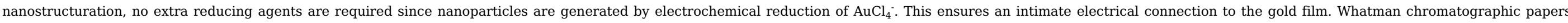

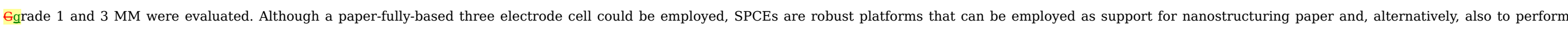

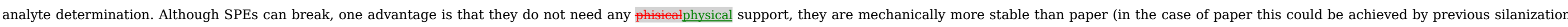

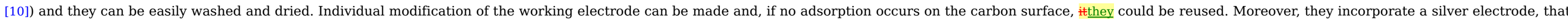
although pseudo-reference, produces stable potentials for the generation of nanoparticles.

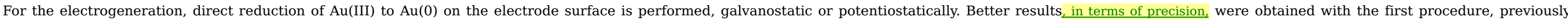

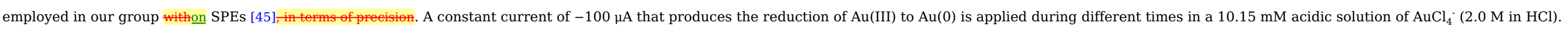

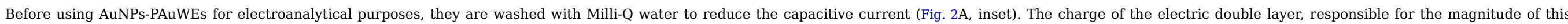

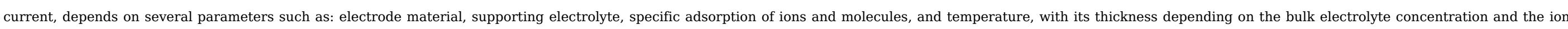

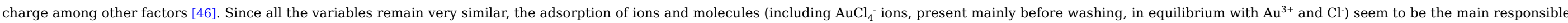
for the change in the capacitive current after washing 


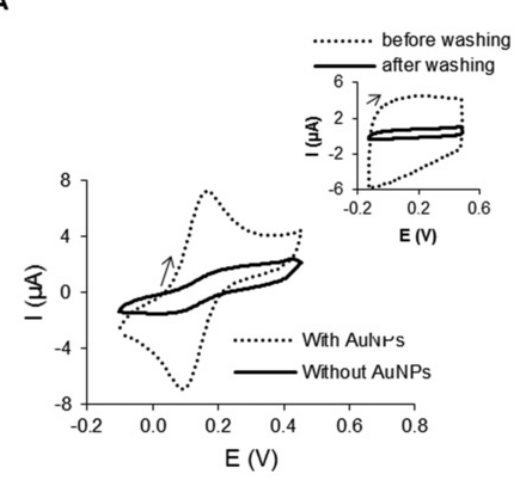

c

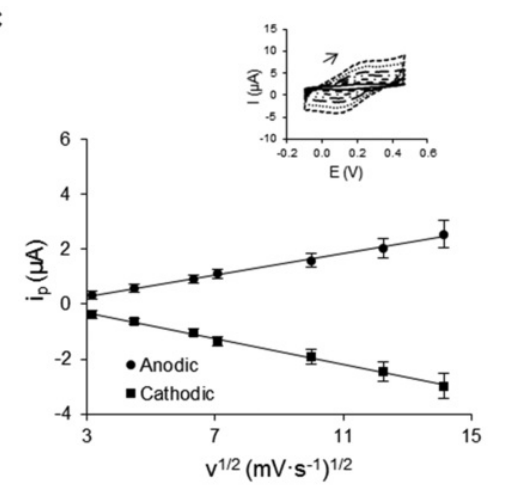

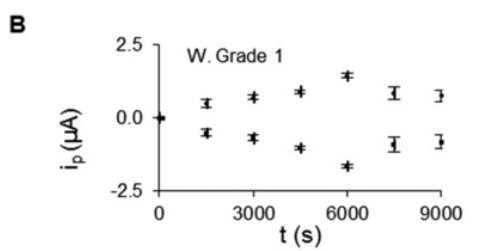
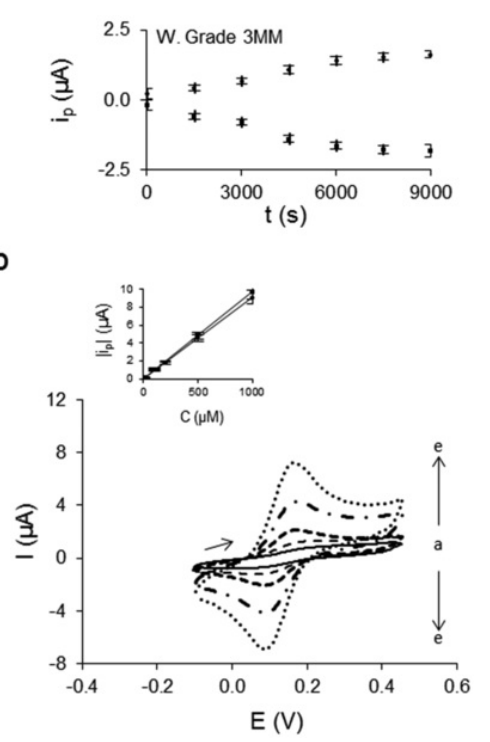

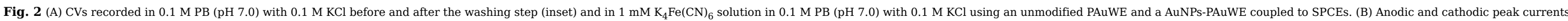

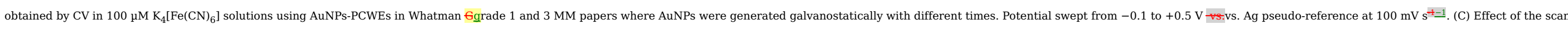

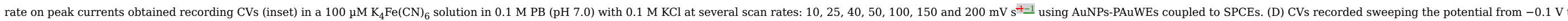
$+0.5 \mathrm{~V}$ at a scan rate of $100 \mathrm{mV} \mathrm{s}^{+-1}$ in $\mathrm{K}_{4} \mathrm{Fe}(\mathrm{CN})_{6}$ solutions of different concentration, increasing from a to $\mathrm{e}$. Inset: Calibration plots of anodic and cathodic peak currents.

\section{alt-text: Fig. 2}

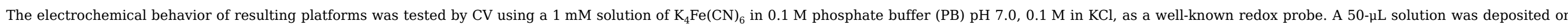

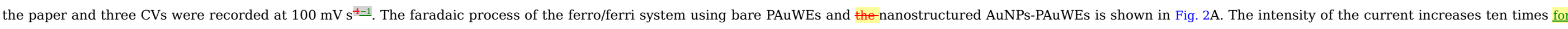

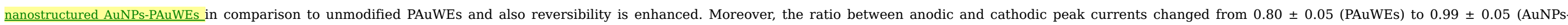

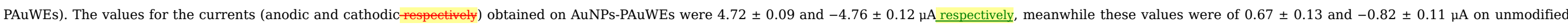

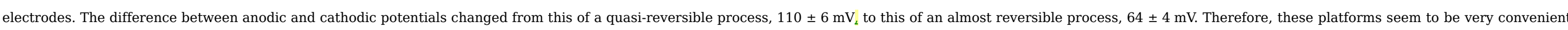

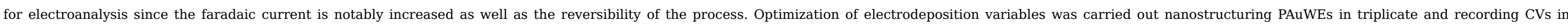

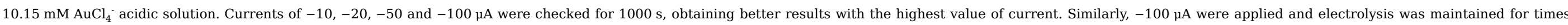

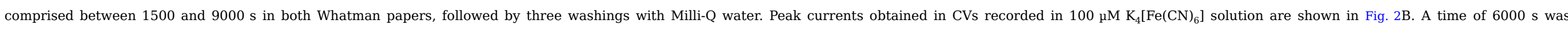

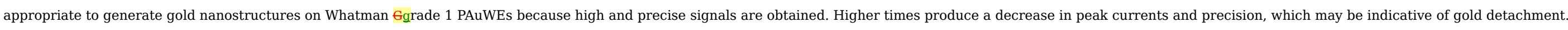

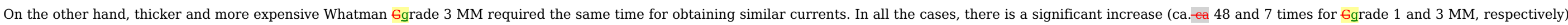

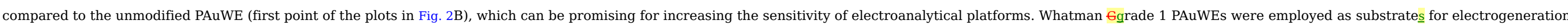




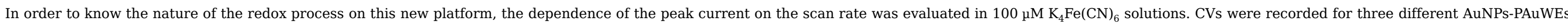

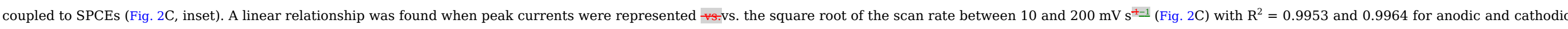

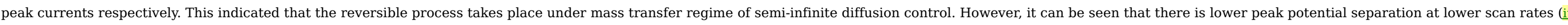

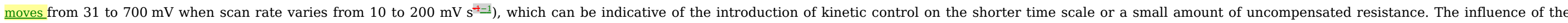

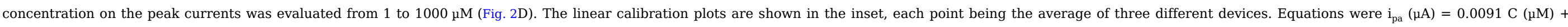

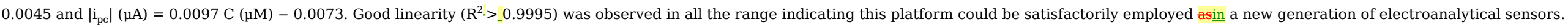

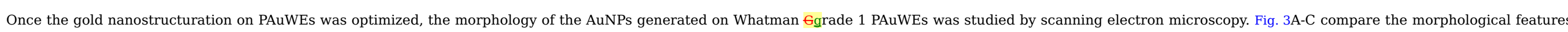

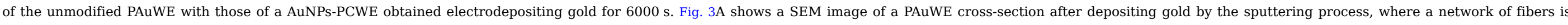

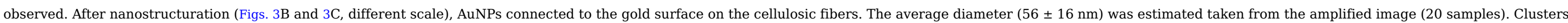
of $170 \pm 44 \mathrm{~nm}$ are also found in some regions.

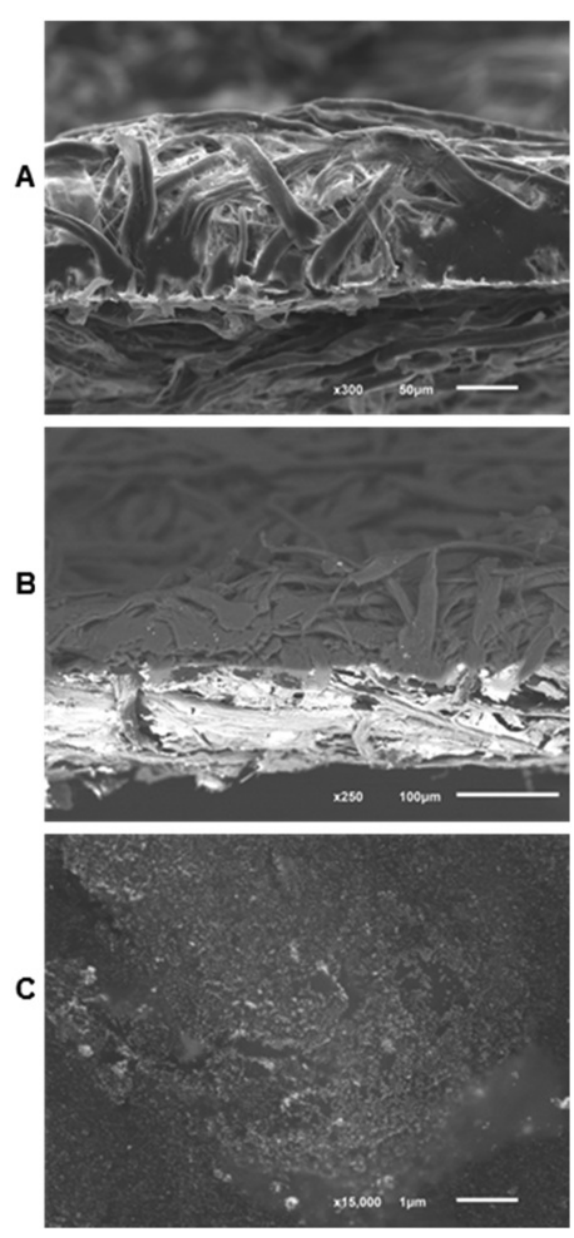




\section{alt-ext: Fig. 3}

\subsection{Non-enzymatic determination of glucose with nanostructured paper-based gold electrodes}

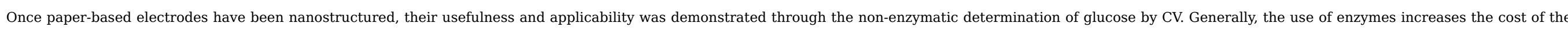

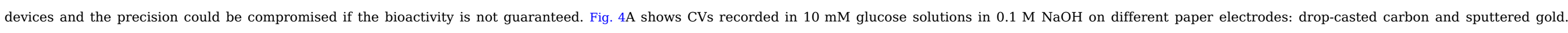

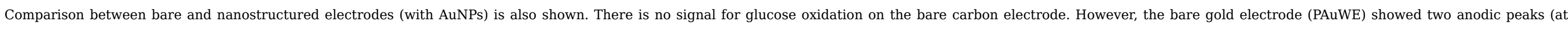

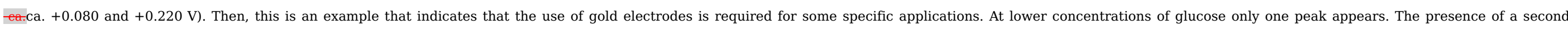

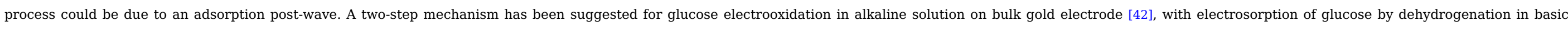

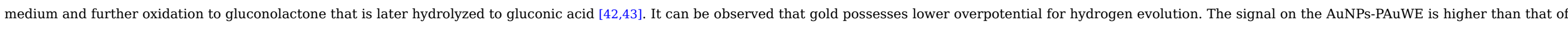

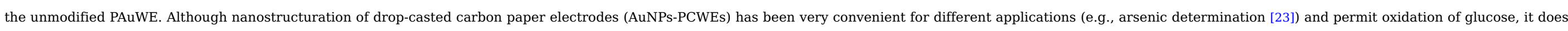
not allow to obtain higher signals than those presented on AuNPs-PAuWEs.

A

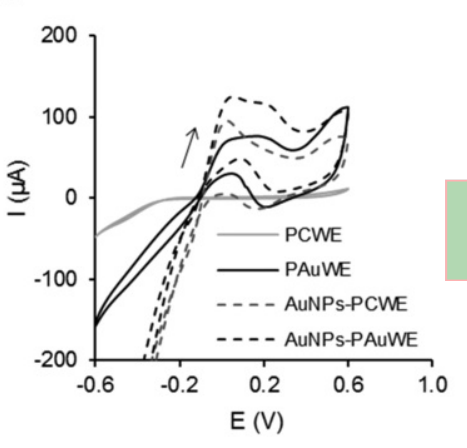

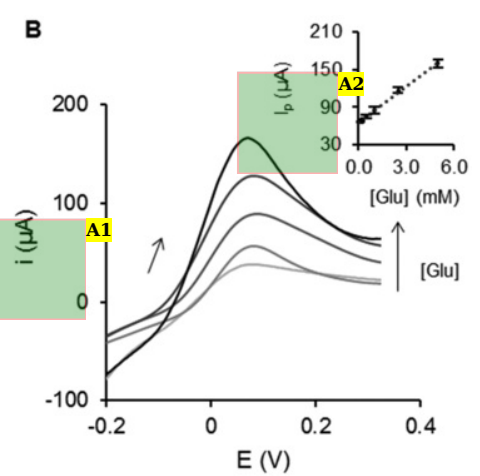

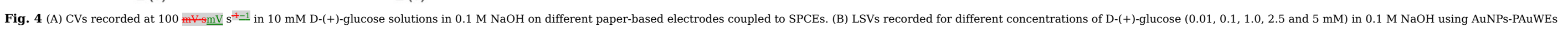

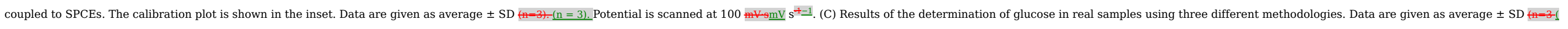
$\underline{\equiv}$ for AuNPs-PAuWEs and spectrophotometric methodologies and $\underline{n-4} \underline{\underline{n}=4}$ for PCWEs).

\section{alt-text: Fig. 4 \\ Annotations: \\ A1. I instead of $\mathrm{i}$ \\ A2. I instead of $i$}

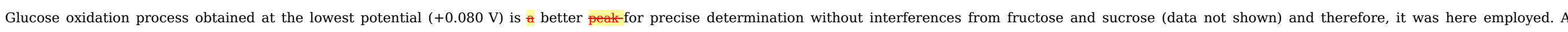

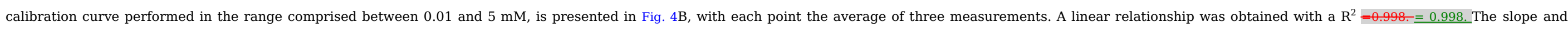

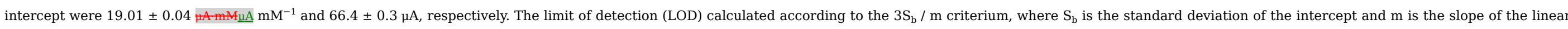
range, was $6 \mu \mathrm{M}$.

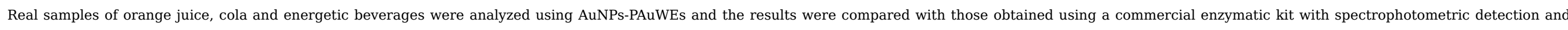

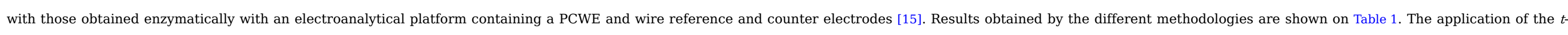

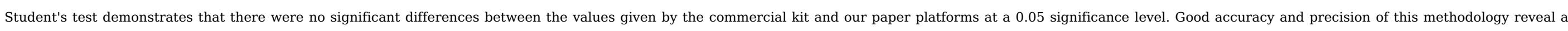




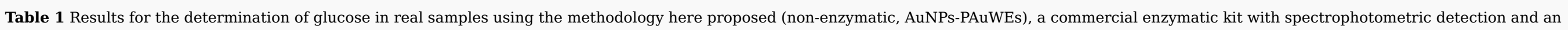
electrochemical platform based on AuNPs-PCWEs with wire RE and CE (enzymatic assay).

\begin{tabular}{|c|c|c|c|}
\hline Real sample & AuNPs-PAuWEs on SPCEs (non-enzymatic, g/100 mL) & PCWEs with wire RE and CE (enzymatic, g/100 mL) & Commercial kit (g/100 mL) \\
\hline Orange juice & $2.8 \pm 0.4$ & $3.0 \pm 0.3$ & $2.9 \pm 0.2$ \\
\hline Energetic beverage & $3.4 \pm 0.3$ & $3.6 \pm 0.4$ & $3.5 \pm 0.2$ \\
\hline Cola beverage & $4.0 \pm 0.5$ & $4.2 \pm 0.7$ & $4.1 \pm 0.3$ \\
\hline
\end{tabular}

Data are given as average $\pm \mathrm{SD}(\mathrm{n}=3 \underline{=3}$ for AuNPs-PAuWEs and the spectrophotometric kit; $\mathrm{n}=\underline{-\mathrm{n}=4} 4$ for PCWEs)PCWEs).

\section{Conclusions}

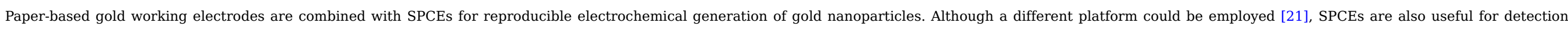

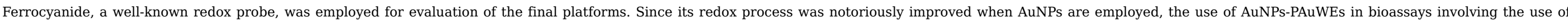

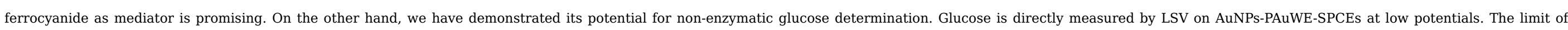

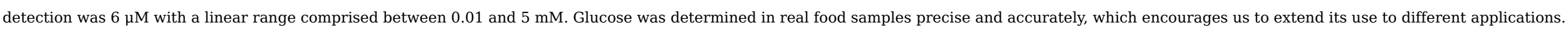

\section{Acknowledgements}

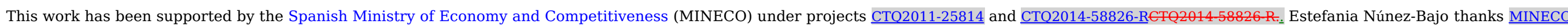
for the award of PhDPh.D. grant BES-2012-056713BES 2012 056713.

\section{References}

[1] R.M. Penner and Y. Gogotsi, The rising and receding fortunes of electrochemists, ACS Nano 10, 2016, 3875-3876.

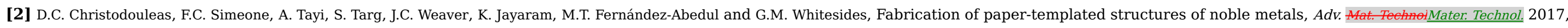
1600229, available online(available online).

[3] M.M. Hamedi, A. Ainla, F. Güder, D.C. Christodouleas, M.T. Fernández-Abedul and G.M. Whitesides, Integrating electronics and microfluidics on paper, $A d v$. Mater. 28, 2016, 5054-5063.

[4] 〈www.micruxfluidic.com〉 (last access on August 20172017).

[5] E. Costa-Rama, A. Costa-García and M.T. Fernández-Abedul, Pin-based flow injection electroanalysis, Anal. Chem. 88, 2016, 9958-9963.

[6] M.T. Fernández-Abedul, J.R. Barreira-Rodríguez, A. Costa-García and P. Tunón-Blanco, Voltammetric determination of cocaine in confiscated samples, Electroanalysis 3, 1991, 409-412.

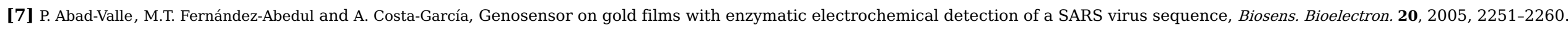

[8] R. García-González, M.T. Fernández-Abedul, A. Pernía and A. Costa-García, Electrochemical characterization of different screen-printed gold electrodes, Electrochim. Acta 53, 2008, 3242-3249.

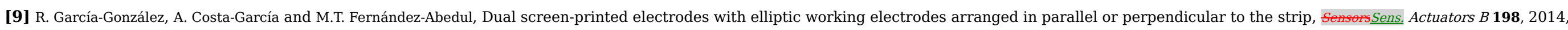
302-308.

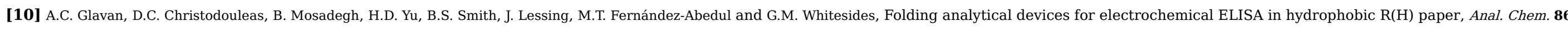
2014, 11999-12007. 
[11] A.W. Martinez, S.T. Phillips, M.J. Butte and G.M. Whitesides, Patterned paper as a platform for inexpensive low-volume, portable bioassays, Angew. ChemieChem. - Int. Ed. 46, 2007, 1318-1320.

[12] W. Dungchai, O. Chailapakul and C.S. Henry, Electrochemical detection for paper-based microfluidics, Anal. Chem. 81, 2009, 5821-5826.

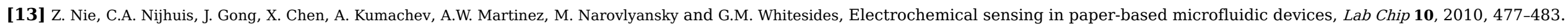

[14] C. Renault, X. Li, S.E. Fosdick and R.M. Crooks, Hollow-channel paper analytical devices, Anal. Chem. 85, 2013, 7976-7979.

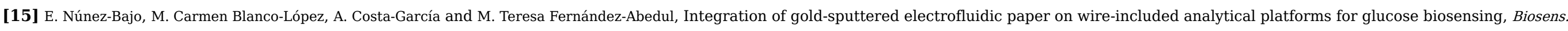
Bioelectron. 91, 2017, 824-832.

[16] J.P. Metters, S.M. Houssein, D.K. Kampouris and C.E. Banks, Paper-based electroanalytical sensing platforms, Anal. Methods 5, 2013, 103-110.

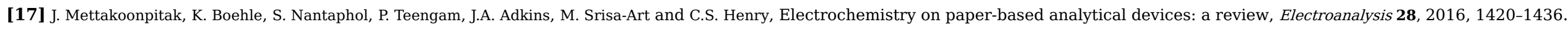

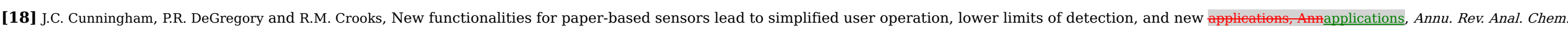
9, 2016, 183-202.

[19] Y. Yang, E. Noviana, M.P. Nguyen, B.J.G. Eiss, D.S. Dandy and C.S. Henry, Paper-based microfluidic devices: emerging themes and applications, Anal. Chem. 89, 2017 , 71-91.

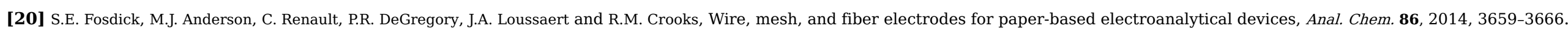

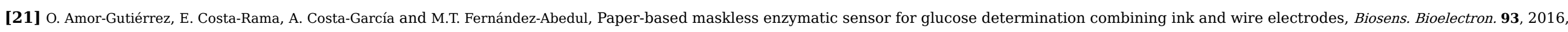
$40-45$.

[22] S. Cinti, D. Talarico, G. Palleschi, D. Moscone and F. Arduini, Novel reagentless paper-based screen-printed electrochemical sensor to detect phosphate, Anal. Chim. Acta 919, 2016 , 78-84.

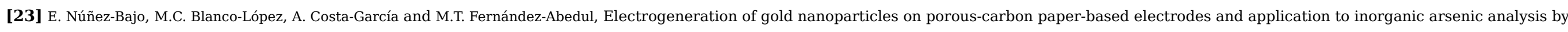
chronoamperometric stripping in white wines, Anal. Chem. 2017, aceepted(in press).

[24] A.C. Siegel, S.T. Phillips, M.D. Dickey, N. Lu, Z. Suo and G.M. Whitesides, Foldable printed circuit boards on paper substrates, Adv. Funct. Mater. 20, 2010 , 28-35.

[25] R.F. Carvalhal, M.K. Simão, M.H.P. de Oliveira, A.L. Gobbi and L.T. Kubota, Electrochemical detection in a paper-based separation device, Anal. Chem. 82, 2010 , $1162-1165$.

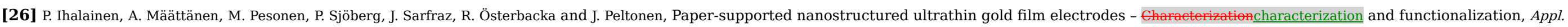
Surf. Sci. 329, 2015, 321-329.

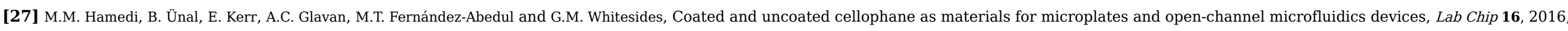
3885-3897.

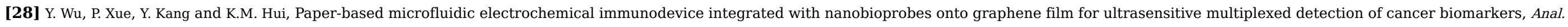
Chem. 85, 2013, 8661-8668.

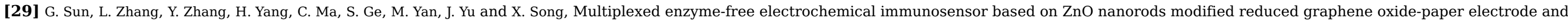
silver deposition-induced signal amplification strategy, Biosens. Bioelectron. 71, 2015, 30-36.

[30] D. Hernández-Santos, M.B. González-García and A. Costa-García, Metal-nanoparticles based electroanalysis, Electroanalysis 14, 2002, 1225-1235.

[31] S.Y. Oh, J. Kim and Y. Kim, Paper-based synthesis of Pd-dendrite supported porous gold, Mater. Lett. 154, 2015, 60-63.

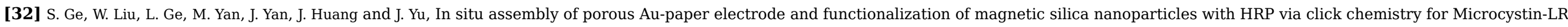
immunoassay, Biosens. Bioelectron. 49, 2013, 111-117. 


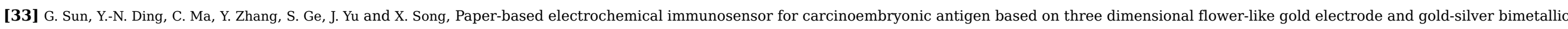
nanoparticles, Electrochim. Acta 147, 2014, 650-656.

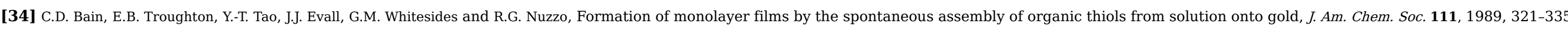

[35] F. Lucarelli, G. Marrazza, A.P.F. Turner and M. Mascini, Carbon and gold electrodes as electrochemical transducers for DNA hybridisation sensors, Biosens. Bioelectron. 19, 2004, 515-530.

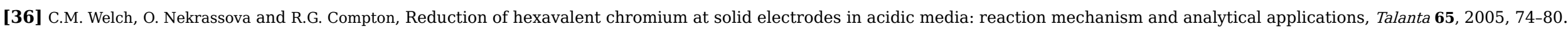

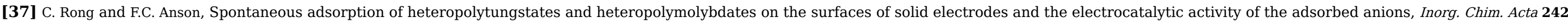
1996, 11-16

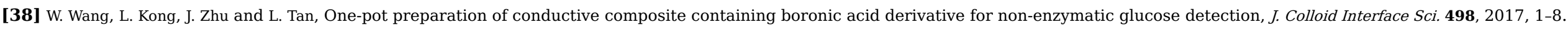

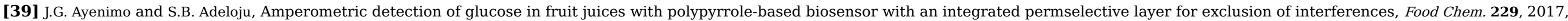
127-135.

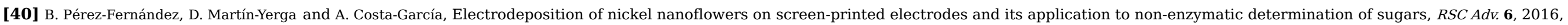
83748-83757.

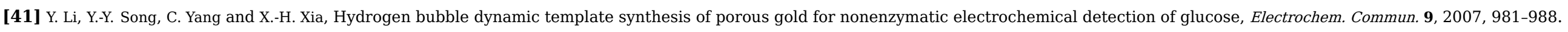

[42] M. Pasta, F. La Mantia and Y. Cui, Mechanism of glucose electrochemical oxidation on gold surface, Electrochim. Acta 55, 2010, 5561-5568.

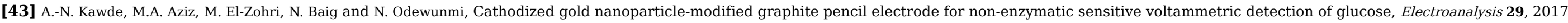
available online(available online)

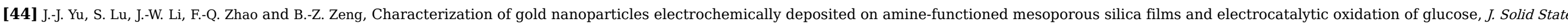
Electrochem. 11, 2007, 1211-1219.

[45] G. Martínez-Paredes, M.B. González-García and A. Costa-García, Lead sensor using gold nanostructured screen-printed carbon electrodes as transducers, Electroanalysis 21, 2009, 925-930.

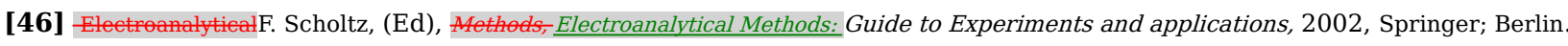

\section{Graphical abstract}

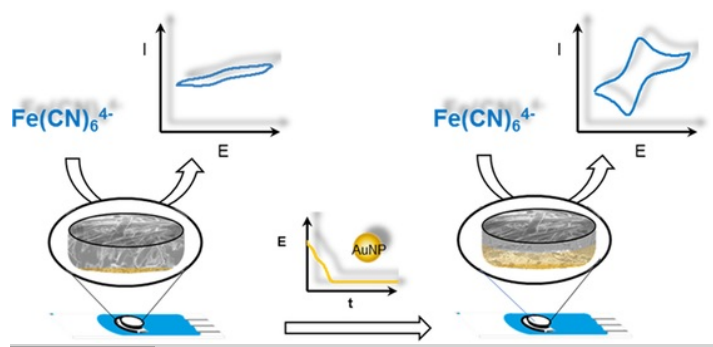


Highlights

- Paper-based electrochemical cell with nanostructured gold filmsfilms.

- Gold nanoparticles electrogenerated on gold-sputtered paper-based

- Simple and low cost paper-based metallic electrode for sensitive

- Non-enzymatic determination of glucose with paper-based nanostructured gold

\section{Queries and Answers}

Query:

Please confirm that given names and surnames have been identified correctly and are presented in the desired order, and please carefully verify the spelling of all authors.

Answer: The given names and surnames are correct and presented in the desired order

Query:

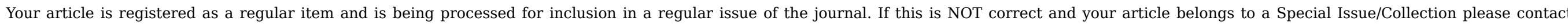
r.saravanakumar@elsevier.com immediately prior to returning your corrections.

Answer: The article is a regular item

Query:

Please verify if the designated corresponding author and email address are correct.

Answer: The designated corresponding author and email address are correct

Query:

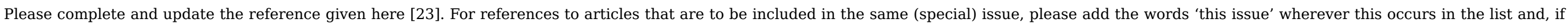
appropriate, in the text.

Answer: The article was published in print (20 June 2017) Anal. Chem. 89, 2017, 6415-6423 